\title{
Novel placement of cortical bone trajectory screws in previously instrumented pedicles for adjacent-segment lumbar disease using CT image-guided navigation
}

\author{
Technical note
}

\author{
Analiz Rodriguez, M.D., Ph.D., Matthew T. Neal, M.D., Ann Liu, B.S., \\ Aravind Somasundaram, B.S., Wesley Hsu, M.D., and Charles L. Branch Jr., M.D. \\ Department of Neurosurgery, Wake Forest University School of Medicine, Winston-Salem, North Carolina
}

\begin{abstract}
Object. Symptomatic adjacent-segment lumbar disease (ASLD) after lumbar fusion often requires subsequent surgical intervention. The authors report utilizing cortical bone trajectory (CBT) pedicle screw fixation with intraoperative CT (O-arm) image-guided navigation to stabilize spinal levels in patients with symptomatic ASLD. This unique technique results in the placement of 2 screws in the same pedicle ( 1 traditional pedicle trajectory and 1 CBT) and obviates the need to remove preexisting instrumentation.

Methods. The records of 5 consecutive patients who underwent lumbar spinal fusion with CBT and posterior interbody grafting for ASLD were retrospectively reviewed. All patients underwent screw trajectory planning with the $\mathrm{O}$-arm in conjunction with the StealthStation navigation system. Basic demographics, operative details, and radiographic and clinical outcomes were obtained.

Results. The average patient age was 69.4 years (range 58-82 years). Four of the 5 surgeries were performed with the Minimal Access Spinal Technologies (MAST) Midline Lumbar Fusion (MIDLF) system. The average operative duration was 218 minutes (range 175-315 minutes). In the entire cohort, 5.5-mm cortical screws were placed in previously instrumented pedicles. The average hospital stay was 2.8 days (range 2-3 days) and there were no surgical complications. All patients had more than 6 months of radiographic and clinical follow-up (range 10-15 months). At last follow-up, all patients reported improved symptoms from their preoperative state. Radiographic follow-up showed Lenke fusion grades of A or B.

Conclusions. The authors present a novel fusion technique that uses CBT pedicle screw fixation in a previously instrumented pedicle with intraoperative O-arm guided navigation. This method obviates the need for hardware removal. This cohort of patients experienced good clinical results. Computed tomography navigation was critical for accurate CBT screw placement at levels where previous traditional pedicle screws were already placed for symptomatic ASLD
\end{abstract}

(http://thejns.org/doi/abs/10.3171/2014.1.FOCUS13521)

\section{KeY Words • O-arm navigation adjacent-segment lumbar disease}

- cortical bone trajectory -
A DJACENT-segment lumbar disease (ASLD) refers to the development of pathology in the mobile segment proximal or distal to a previous lumbar fusion. Adjacent pathology includes disc degeneration, disc herniation, listhesis, instability, stenosis, hypertrophic facet arthritis, scoliosis, and vertebral compression fracture..$^{7,13}$ The prevalence of ASLD is widely variable in the literature as some studies refer to radiographic rather than symptomatic disease. ${ }^{3} \mathrm{~A}$ recent meta-analysis review reports the prevalence of symptomatic ASLD to

\footnotetext{
Abbreviations used in this paper: ASLD = adjacent-segment lumbar disease; $\mathrm{CBT}=$ cortical bone trajectory; MAST $=$ Minimal Access Spinal Technologies; MIDLF = Midline Lumbar Fusion.
}

be $8.5 \% .^{24} \mathrm{~A}$ large portion of these patients will require reoperation to address symptomatic ASLD. ${ }^{4}$

Subsequent operative intervention to treat ASLD usually includes decompression and fusion of adjacent spinal levels. During surgery for ASLD, it is not unusual to expose all of the preexisting hardware, which leads to significant pain and may potentially increase the risk of infection and need for perioperative blood transfusion. The cortical bone trajectory (CBT) technique can be used to avoid extensive tissue dissection by limiting the surgical corridor to the levels adjacent to the existing hardware. Cortical bone trajectory was developed to increase screw-bone purchase during posterior pedicle fixation. ${ }^{10,16}$ Because the starting point for CBT screws is at the lateral aspect of the pars interarticularis, there is less need 
for tissue muscle dissection..$^{10}$ The CBT screws are then placed with medial to lateral angulation as opposed to the lateral to medial angulation used in the traditional pedicle trajectory. These technical differences between CBT and traditional pedicle trajectory allow for posterior fixation with CBT to be performed in a smaller operative corridor. This allows CBT to be easily incorporated into minimally invasive techniques. Minimally invasive surgical techniques provide multiple advantages, which include less tissue trauma and less recovery time. $.^{19,23} \mathrm{Re}-$ cently, minimally invasive surgery has been coupled with advancements in image-guided technologies. ${ }^{12}$

In this study, we combine neuronavigation and CBT to treat patients with symptomatic ASLD. We describe 5 patients with symptomatic ASLD who underwent navigated CBT pedicle bone screw fixation to stabilize adjacent spinal levels. This unique technique resulted in a spinal level in which 1 pedicle was instrumented with 2 screws (1 traditional pedicle screw and 1 CBT screw), and negated the need to remove preexisting hardware. We also provide a technical guide for spine surgeons who want to incorporate this novel technique into their armamentarium.

\section{Methods}

\section{Data Collection}

After approval from the institutional review board of Wake Forest University, a retrospective review of patients who underwent lumbar fusion by a single surgeon (the senior author) using CBT was conducted. Eighty-five patients had undergone lumbar fusion with CBT from August 2011 to March 2013. Of these patients, only 5 had undergone lumbar fusion for ASLD with CT-guided intraoperative navigation. Basic demographics, including surgical indications, are presented in Table 1.

\section{Surgical Procedure}

All but 1 patient underwent exposure of the spinal level to be fused with the Minimal Access Spinal Technologies (MAST) Midline Lumbar Fusion (MIDLF) system (Medtronic). Intraoperative navigation was performed using a 3D O-arm system (Medtronic Navigation) in conjunction with the StealthStation navigation system (Medtronic Navigation). After exposure, the reference

TABLE 1: Patient demographics of cohort*

\begin{tabular}{cccclcl}
\hline $\begin{array}{c}\text { Case } \\
\text { No. }\end{array}$ & $\begin{array}{c}\text { Age (yrs), } \\
\text { Sex }\end{array}$ & $\begin{array}{c}\text { ASA } \\
\text { Class }\end{array}$ & $\begin{array}{c}\text { BMl } \\
\text { Indication }\end{array}$ & $\begin{array}{c}\text { Surgical } \\
\text { Fusion Levels }\end{array}$ & $\begin{array}{c}\text { Previous } \\
\text { w/ CBT }\end{array}$ \\
\hline 1 & $58, \mathrm{M}$ & 2 & 30.5 & ALS, DSC & L4-S1 & L3-4 \\
2 & $69, \mathrm{~F}$ & 3 & 25.8 & ALS, SL & L3-S1 & L2-3 \\
3 & $82, \mathrm{M}$ & 3 & 34.2 & ALS, DSC & L3-S1 & L2-3 \\
4 & $66, \mathrm{M}$ & 3 & 30.1 & ALS, DSC & L2-5 & L5-S1 \\
5 & $72, \mathrm{~F}$ & 2 & 23.9 & ALS, SL & L4-S1 & L3-4 \\
\hline
\end{tabular}

* ALS = adjacent-level stenosis; ASA = American Society of Anesthesiologists; $\mathrm{BMI}=$ body mass index; $\mathrm{DSC}=$ disc space collapse; $\mathrm{SL}=$ spondylolisthesis. frame was attached to the spinous process above the level to be fused (Fig. 1). Prior to CBT screw placement, an intraoperative CT (O-arm) scan was obtained and these images were transferred to the navigation station. Cortical bone trajectory for pedicle fixation was navigated using the StealthStation (Fig. 2). Cortical bone trajectories were also navigated in pedicles with a preexisting screw (Figs. 3 and 4). After trajectories were planned, bilateral hemilaminectomies and medial facetectomies were performed at the level to be fused to gain access to the disc space. Capstone or Capstone Control interbody grafts (Medtronic) were placed prior to placing screws and rods.

Clinical postoperative follow-up and radiographic imaging was reviewed for all patients. Lenke fusion grade was determined from analysis of radiographic imaging. The Lenke fusion grade is used to categorize radiographic fusion patterns. Grade A denotes solid trabeculated bilateral fusion masses, Grade B denotes unilateral large fusion mass with contralateral small fusion mass, Grade $\mathrm{C}$ denotes small, thin fusion masses bilaterally, and Grade D denotes graft resorption bilaterally or obvious pseudarthrosis. The Lenke fusion grade was determined by 2 independent spine surgeons. ${ }^{6}$

\section{Illustrative Case}

Case 1

A 58-year-old man who had previously undergone an L4-S1 fusion in November of 2003 presented with severe back and leg pain consistent with neurogenic claudication. Preoperative MRI demonstrated a large disc herniation, overgrown facets, and ligament flavum hypertrophy, causing severe stenosis with nearly complete block of the spinal canal at the L3-4 level (Fig. 5). The patient underwent L3-4 lumbar fusion with interbody grafting and CBT screw navigation with the intraoperative $\mathrm{O}$-arm. Postoperative imaging demonstrated ideal placement of cortical screws (Fig. 6). The patient had a hospital stay of 2 days. At last postoperative follow-up (15 months from

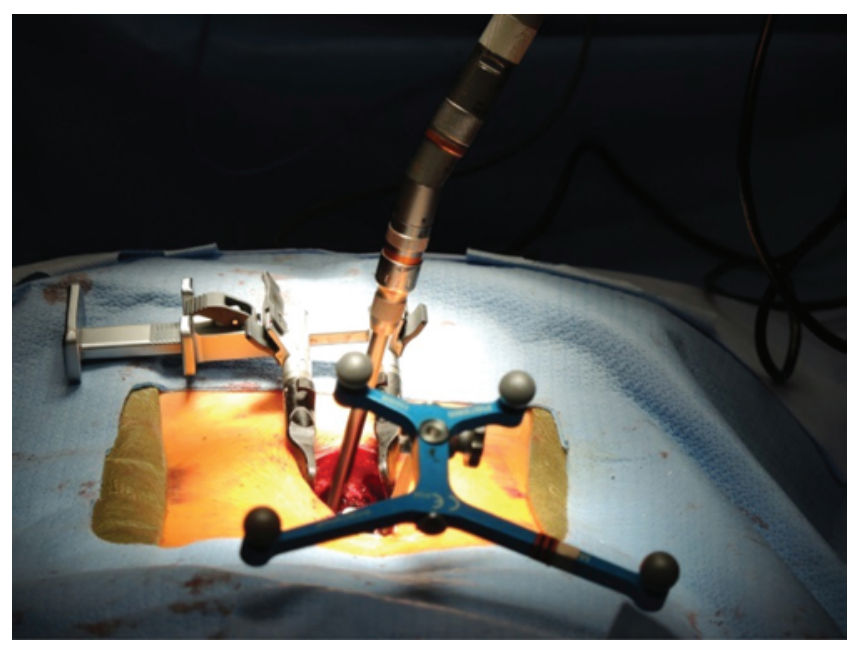

FIG. 1. Intraoperative photograph showing the setup with the MAST MIDLF retractor and navigation tracking device. The MAST MIDLF retractor provides adequate exposure for instruments to fit easily. 


\section{Cortical bone trajectory screws for ASLD using spinal navigation}

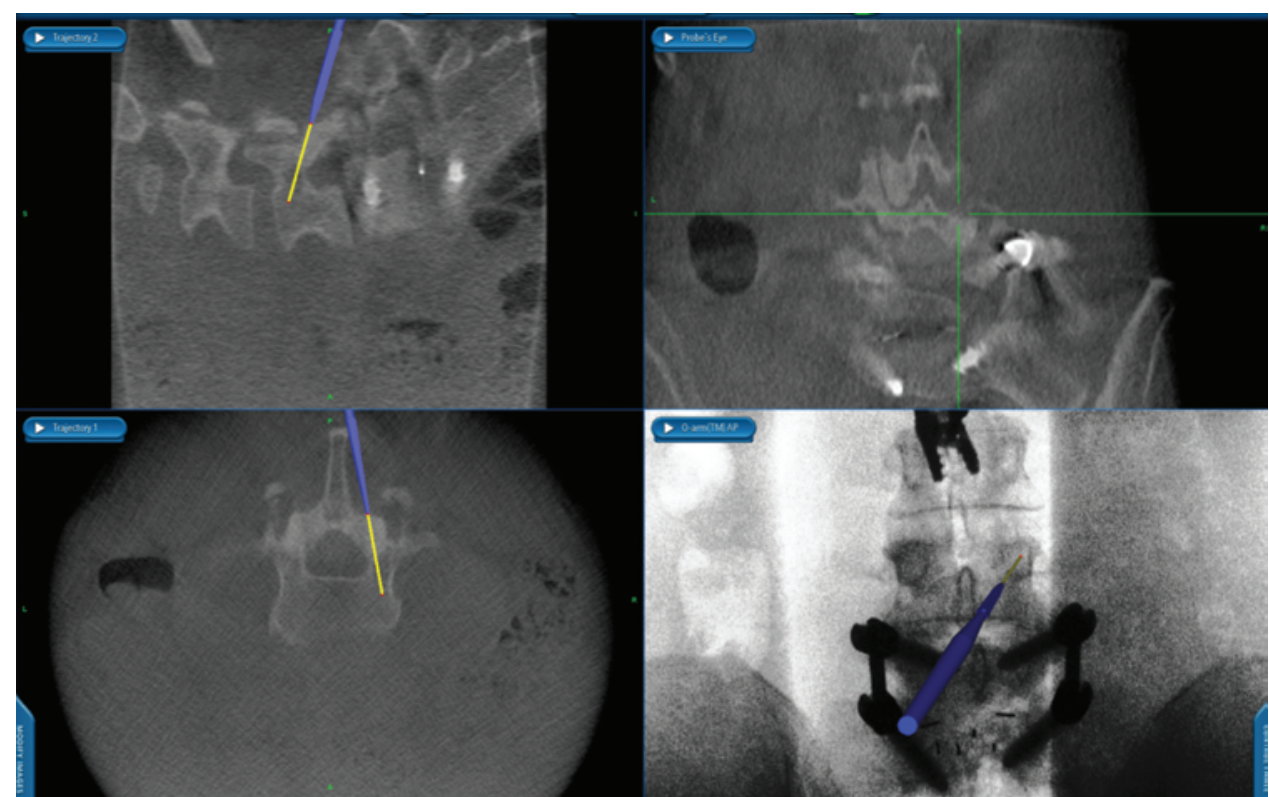

FIG. 2. Cortical bone trajectories were navigated with the 0 -arm and stealth navigation. These screenshots demonstrate the medial to lateral angulation of the left L-3 CBT along the pedicle (upper left = sagittal view, upper right = coronal view, lower left = axial view, lower right = anteroposterior view). This patient had previously undergone L4-5 fusion with traditional pedicle fixation.

surgery) the patient remained asymptomatic and was discharged from the clinic.

\section{Results}

Of the 5 patients who underwent CBT lumbar fusion for ASLD using spinal navigation, 2 were female and 3 were male. The average age of the cohort was 69.4 years (range 58-82 years). All patients had previously undergone lumbar fusion with traditional pedicle fixation. Pre- operative assessment showed that the patients had a range of diagnoses contributing to their ASLD and stenosis (Table 1). However, all patients had adjacent-level stenosis.

The average operative duration was 218 minutes (range 175-315 minutes). Four of 5 surgeries were performed using the MAST MIDLF system. Only 1 surgery was performed using traditional open access. Estimated blood loss was less than $500 \mathrm{ml}$ for all but 1 surgery (Table 2). One patient had an estimated blood loss of $650 \mathrm{ml}$, which was secondary to excessive bleeding from harvest-

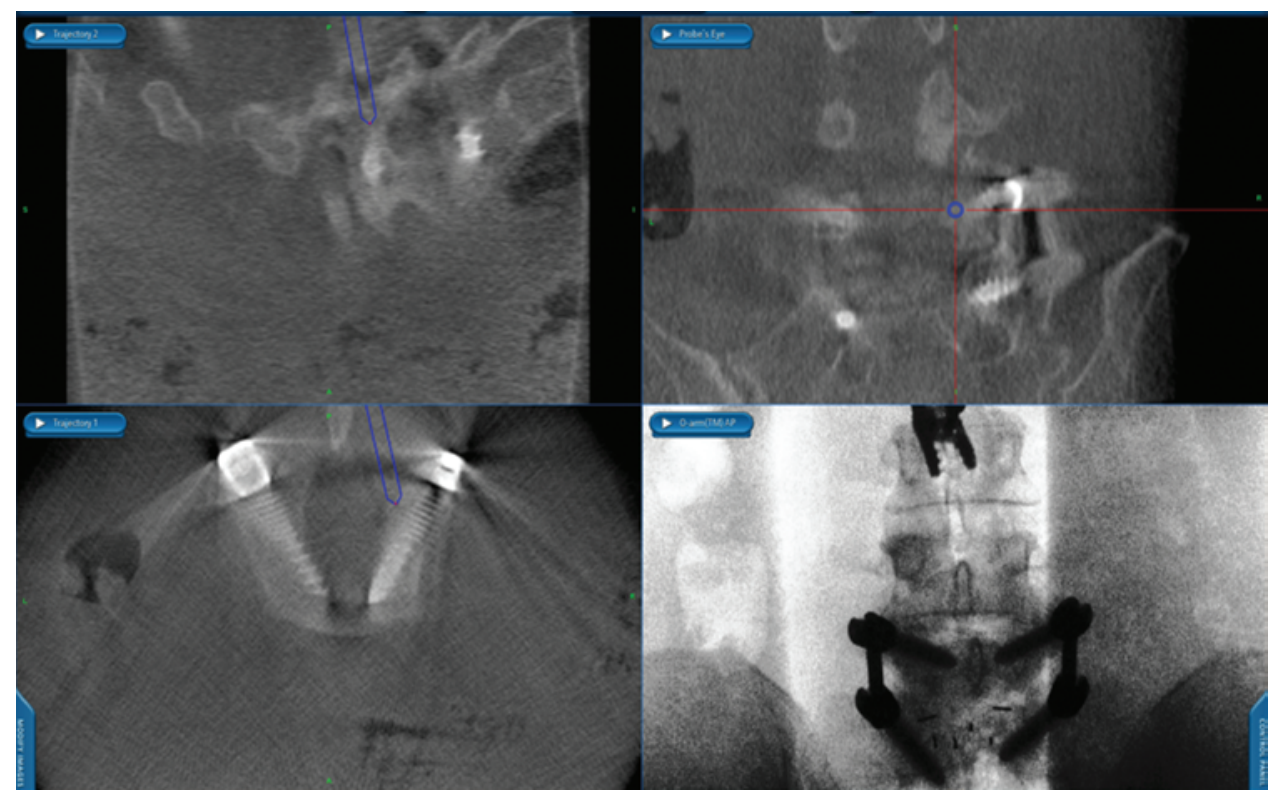

FIG. 3. Cortical bone trajectories were also navigated in pedicles that had a preexisting screw. The new CBT screw was navigated superior to the previously placed traditional pedicle screw. These screenshots demonstrate navigation of a left L-4 cortical screw in a patient who had previously undergone L4-5 posterior fixation (upper left = sagittal view, upper right = coronal view, lower left = axial view, lower right $=$ anteroposterior view). 


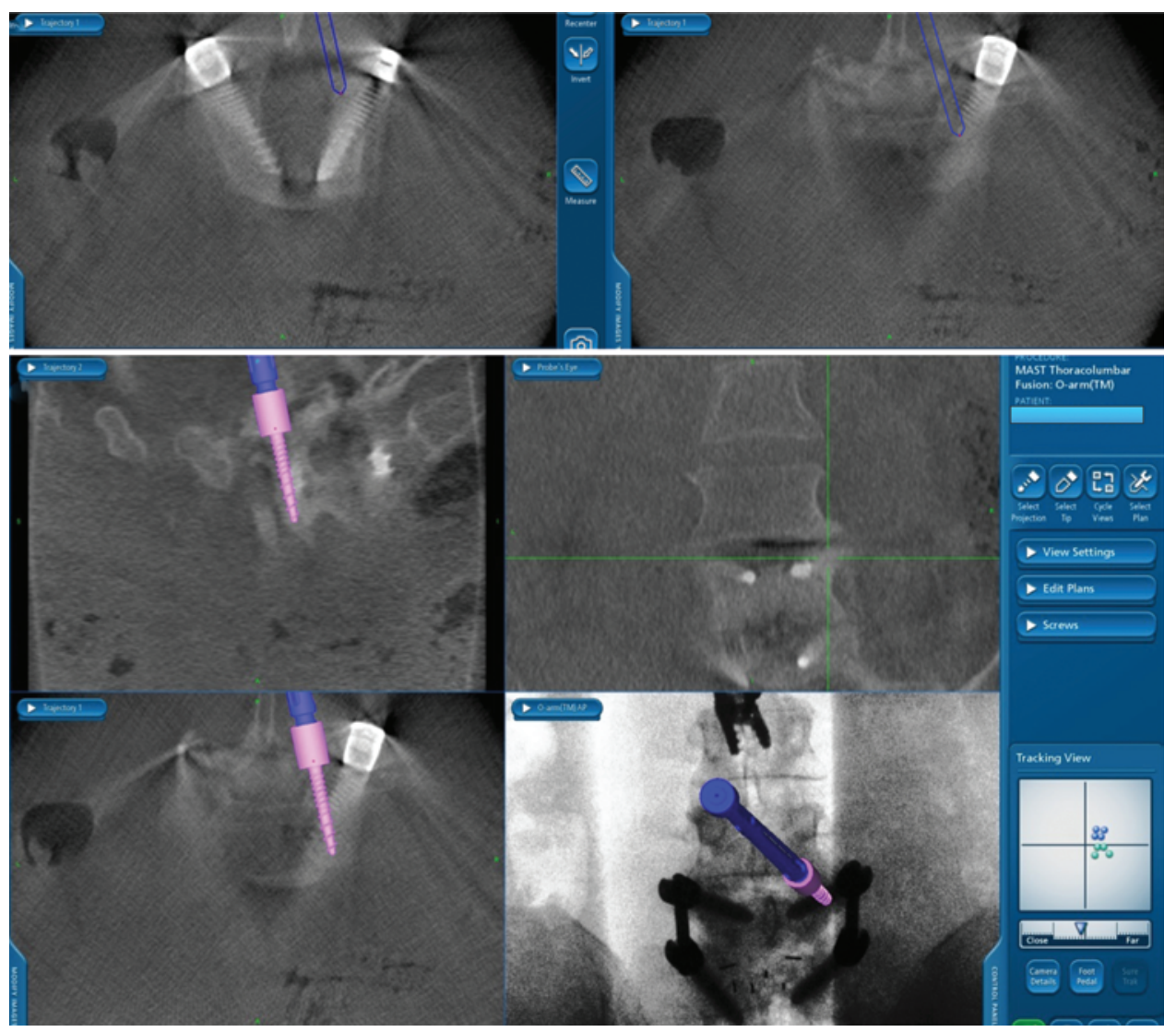

FIG. 4. Cortical bone trajectory navigation in a pedicle with a previously placed pedicle screw. Axial images (upper row) demonstrate the path of the trajectory during tapping of the pedicle. The lower rows show navigational screw placement along the CBT in the axial and sagittal views (upper left = sagittal view, upper right = coronal view, lower left = axial view, lower right = anteroposterior view).

ing bone autograft from the previously fused construct. Cortical screw size at the level of previous instrumentation was $5.5 \mathrm{~mm}$ in diameter for all cases (Table 2). There were no postoperative complications and all patients were discharged home with an average hospital stay of 2.8 days (range 2-3 days; Table 3 ). The patients' index surgery was on average 6.6 years (range 3-13 years) prior to their revision surgery for ASLD (Table 2).

All patients had more than 6 months of radiographic and clinical follow-up. Average follow-up was 12.2 months (range 10-15 months). All patients had Lenke fusion grades of A or B at last follow-up. All patients in the cohort endorsed improved symptoms at their last clinical visit (Table 3). Two of 5 patients endorsed complete resolution of preoperative symptoms. One patient (Case 1) was discharged from the clinic given his improvement. Three of 5 patients had a decrease in the number of medications (prescription pain medicine and/or muscle relaxants) taken for symptom relief (Table 3).

\section{Discussion}

Adjacent-segment disease is defined as new symptoms that are referable to an adjacent level after patients have undergone successful surgical intervention at an index level. Several hypotheses exist to explain the cause of adjacent-segment disease. In patients who have previously undergone fusion, it is believed that the increased biomechanical demand on the adjacent levels contributes to the development of adjacent-segment disease. ${ }^{5,13,15}$ However, it is not known if adjacent-segment disease is a sequela of the natural history of spinal degenerative disease or secondary to iatrogenic changes of spinal biomechanics following surgery.

Whether the rate of ASLD is increased following fusion is controversial. Disparate results in the literature exist on the incidence of ASLD following previous lumbar fusion. ${ }^{1,11}$ Laminectomy adjacent to a lumbar fusion construct and a longer length of fusion construct are considered risk factors for the development of ASLD. The method of fusion has not been shown to correlate with the rate of ASLD..$^{15}$ There are few reports in the literature on the incidence of ASLD requiring subsequent surgical intervention. One study reported that $20 \%$ of patients required a second surgery for ASLD following posterolateral fusion after a minimum of 5 years of follow-up. ${ }^{2}$ The interval between index surgery and subsequent surgery for ASLD has been reported to be in a range from 5 to 7 years. ${ }^{5}$ In our small cohort, the range was from within 3 years to as many as 13 years (Table 2). This wide variability is likely secondary to the differential diagnoses and initial index surgery among the patient population.

The CBT is a relatively novel fixation technique that was developed to enhance screw-bone purchase with 

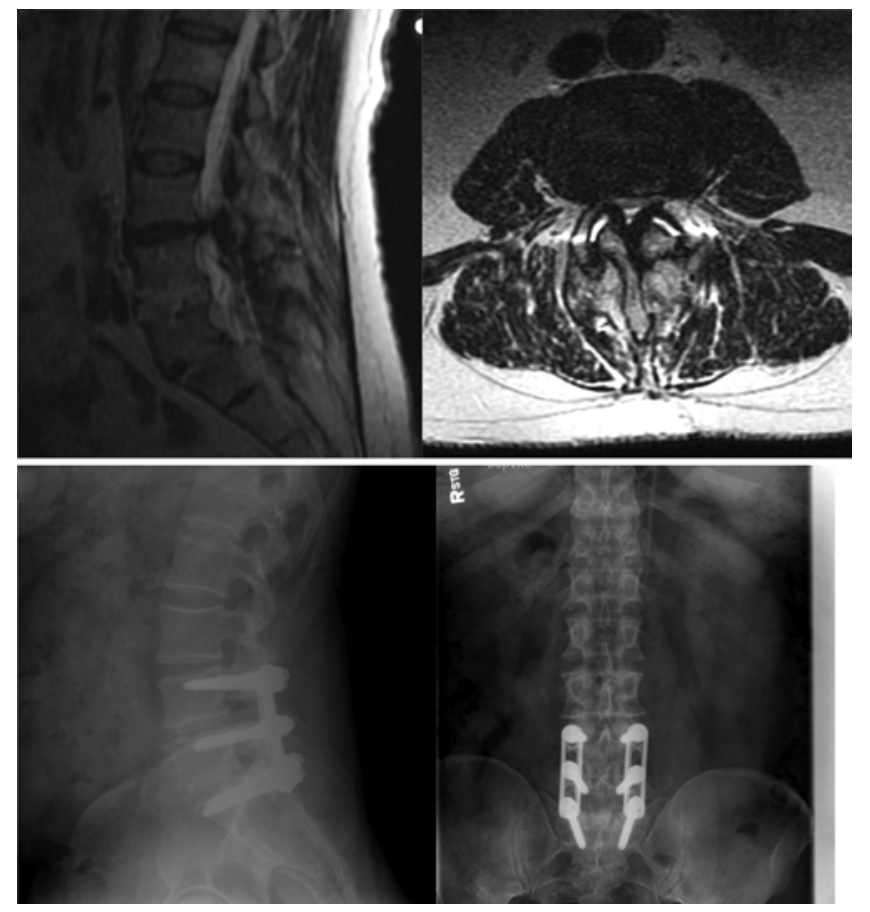

FIG. 5. Case 1. Preoperative MRI and radiographic images. Upper: Sagittal (left) and axial (right) MR images demonstrate adjacentlevel disc collapse and stenosis at L3-4 in a patient with previous L4-S1 fusion. Lower: Lateral (left) and anteroposterior (right) radiographs demonstrate the preexisting fixation hardware.

minimal soft-tissue dissection. The CBT starts at the lateral part of the pars interarticularis and follows a caudocephalad and laterally directed path., ${ }^{9,16}$ Initial biomechanical analyses demonstrated that CBT had equivalent pullout and toggle characteristics in comparison with traditional pedicle screw trajectory. ${ }^{16}$ Uniaxial yield pullout load was $30 \%$ higher in the CBT screws in comparison with traditional trajectory pedicle screws. ${ }^{16}$ In a recent study, CBT constructs with interbody grafting provided the same stability as constructs with pedicle screw fixation. ${ }^{14}$ These biomechanical analyses were performed in cadaveric lumbar spines. In an in vivo analysis, the insertional torque with CBT is approximately 1.7 times higher than with the traditional pedicle trajectory technique. Insertional torque has been correlated with screw stability. ${ }^{8}$ The higher cortical bone density interface of CBT screws results in an increase in interface strength per unit screw length. Therefore, fixation is independent of the bone trabecular quality that makes CBT an attractive option for patients with osteoporosis. ${ }^{16,21}$ Ueno et al. performed a corrective lumbar fusion using a double screw trajectory in a patient with degenerative scoliosis and osteoporosis. At each level, the patient had both a CBT screw and a traditional pedicle screw placed. ${ }^{21}$ Prior to our study, this was the only known case in the literature to date that has reported pedicle fixation with this double trajectory technique.

In our study we used the CBT for our pedicle screw fixation in adjacent-level fusion constructs for patients with ASLD. This technique eliminates the need to expose, remove, or connect to preexisting hardware, with
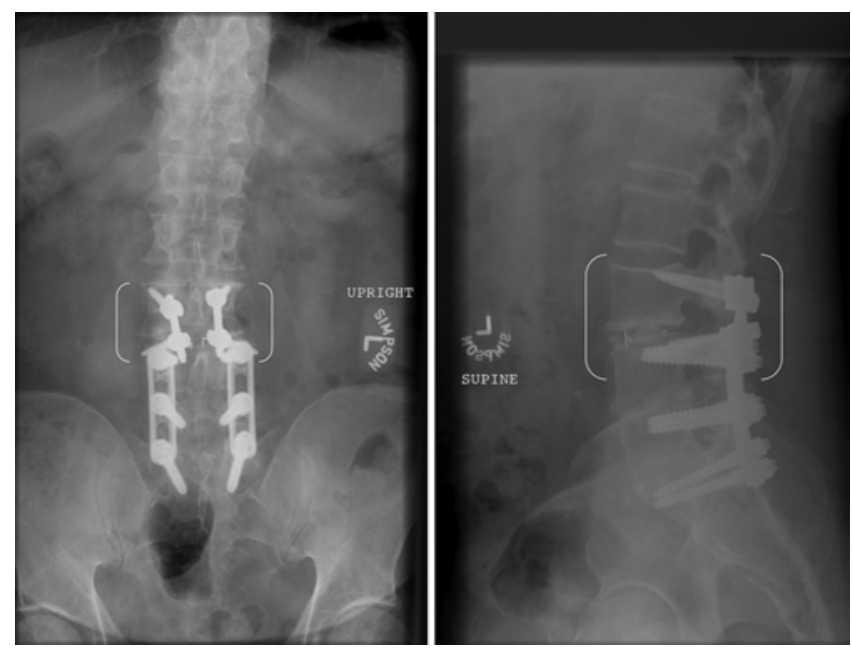

FIG. 6. Case 1. Postoperative anteroposterior (left) and lateral (right) radiographs following fusion at L3 -4 using CBT with navigation. The L-4 vertebral body now has 2 screws placed in each pedicle via a CBT and traditional pedicle trajectory.

anticipated benefits of reduced operative time, blood loss, and dissection. At one level the pedicles must now accept 2 screws (1 CBT and 1 traditional pedicle trajectory). A key element in patient selection is determining whether a pedicle with a preexisting pedicle screw can accommodate a CBT pedicle screw. Pedicle size, along with the pedicular placement of the existing screw, is a critical determinant of whether a second screw may be added safely. A preoperative CT scan is very helpful in this regard, as the amount of residual, uninstrumented pedicle can be determined with accuracy. Because the smallest corticalthreaded pedicle screw is $4.5 \mathrm{~mm}$, we believe a residual cortical-transpedicle pathway of at least $5.0 \mathrm{~mm}$ in diameter is adequate to accommodate a CBT screw. Cadaveric studies are needed to determine the minimum amount of residual pedicle necessary for adequate screw purchase when placing the second screw in this novel technique.

During intraoperative planning, the preoperative lateral plain radiograph may show sufficient pedicle above or below an existing screw. This view is enhanced with a sagittal reconstruction using $\mathrm{CT}$. The $\mathrm{O}$-arm 3D neuronavigation system provides real-time anatomical guidance for placing a new CBT screw in a pedicle with a preexisting traditional pedicle trajectory screw. This real-time imaging also informs the surgeon that this approach may not be used and that an alternative fixation technique must be considered. O-arm navigation is also particularly helpful for surgeons who are gaining familiarity with this technique. The narrow corridor of a residual pedicle is a challenge to navigate using a freehand technique, although it is certainly viable as a surgeon gains experience. The real-time trajectory and anatomical guidance reduces the risk of pedicle breach that would be inherent without navigation during screw placement, given the anatomical constraints. In cadavers without deformity or prior instrumentation, there was no difference between $\mathrm{O}$-arm or $\mathrm{C}$-arm use in breach rates when placing thoracic and lumbosacral pedicle screws. ${ }^{20}$ However, many studies support neuronavigation in improving 
TABLE 2: Operative details of cohort*

\begin{tabular}{cccccccc}
\hline $\begin{array}{c}\text { Case } \\
\text { No. }\end{array}$ & Approach $†$ & $\begin{array}{c}\text { Previous Pedicle } \\
\text { Screw Size }(\mathrm{mm}) \ddagger\end{array}$ & $\begin{array}{c}\text { Cortical Screw } \\
\text { Size }(\mathrm{mm}) \ddagger\end{array}$ & $\begin{array}{c}\text { Index Surgery } \\
(\mathrm{yr})\end{array}$ & $\begin{array}{c}\text { Adjacent-Level } \\
\text { Surgery }(\mathrm{yr})\end{array}$ & $\begin{array}{c}\text { EBL }(\mathrm{ml}) \\
\text { Time }(\mathrm{min})\end{array}$ \\
\hline 1 & MAST & $7.0 \times 45$ & $5.5 \times 35$ & 2003 & 2011 & 150 & 186 \\
2 & MAST & $7.0 \times 45$ & $5.5 \times 35$ & 2008 & 2011 & 250 & 238 \\
3 & MAST & $7.5 \times 45$ & $5.5 \times 35$ & 2008 & 2011 & 300 & 175 \\
4 & open & $7.0 \times 40$ & $5.5 \times 35$ & 1998 & 2011 & 300 & 176 \\
5 & MAST & $7.5 \times 45$ & $5.5 \times 30$ & 2006 & 2012 & 650 & 315 \\
\hline
\end{tabular}

* EBL $=$ estimated blood loss.

† All patients underwent spinal navigation with the intraoperative 0-arm.

$\ddagger$ Pedicle screw and cortical screw sizes reported are at the level where double screws were placed.

screw placement. ${ }^{17,18,22}$ In the technique used in this study, we surmise that the same accuracy benefits of using $\mathrm{O}$ arm navigation are derived in the CBT screw placement, where increased accuracy is mandated due to the existing pedicle screw.

Besides considerations regarding the amount of residual pedicle when performing the double pedicle screw technique, there are no unique contraindications to using the CBT technique compared with a traditional pedicle screw trajectory. The advantages of the limited dissection necessary using this technique make it ideal in high-risk patients, including the morbidly obese and diabetic population. Initial biomechanical studies on CBT also make this attractive for osteoporotic patients given the increase in cortical bone purchase. . $^{16,21}$

We have yet to use this method for multilevel ASLD or ASLD with spinal deformity. We have been successful in treating both proximal and distal ASLD but would suggest caution in attempting this technique with a multilevel lumbar fusion and ASLD at L5-S1. Patients have been treated for proximal ASLD at levels up to L-2 but these data are not included in this paper because we did not use spinal navigation for these patients. The unique pedicle anatomy in the upper lumbar spine mandates careful review of the existing fusion and pedicle screw interface on intraoperative radiographic imaging. We have used interbody grafts with all our surgeries as our patients benefitted from the restoration of disc height or sagittal or coronal alignment. We are concerned that the CBT in ASLD may be prone to "toggling" without an interbody graft. However, this concern is not supported by cadaveric biomechanical data, and we are currently studying this question in the laboratory.
Our cohort had an average hospital stay of 2.8 days. We presume that not exposing previously placed hardware contributed to a reduction in operative time, and thus a decreased hospital stay. Further prospective studies need to be conducted to verify this hypothesis. All patients endorsed symptom improvement compared with their preoperative state at last follow-up. Limitations of our study include the small cohort and its retrospective nature. No verified questionnaires to determine functional status were used in our outcome assessment. In the future, we would like to collect these data prospectively.

\section{Conclusions}

The treatment of symptomatic ASLD remains heterogeneous and we present a novel fusion technique that uses CBT pedicle screw fixation in a previously instrumented pedicle with CT-guided navigation. This method negates the need for hardware removal. Our cohort of patients did well postoperatively and had evidence of radiographic fusion on follow-up. Computed tomography navigation was critical for accurate screw placement at levels in which double screws were present in a single pedicle.

\section{Acknowledgments}

We extend our thanks to Andy Elliott, Medtronic representative, for providing information on the Medtronic technologies used in this study. We also thank Denise Sprinkle, radiology technician, for her help with the neuronavigation.

\section{Disclosure}

Dr. Charles L. Branch Jr. is a consultant for Medtronic. He also

TABLE 3: Postoperative details of cohort*

\begin{tabular}{ccccccccc}
\hline $\begin{array}{c}\text { Case } \\
\text { No. }\end{array}$ & $\begin{array}{c}\text { Hospital } \\
\text { Stay (days) }\end{array}$ & $\begin{array}{c}\text { Radiographic } \\
\text { Follow-Up (mos) }\end{array}$ & $\begin{array}{c}\text { Lenke } \\
\text { Fusion Grade }\end{array}$ & $\begin{array}{c}\text { Clinical } \\
\text { Follow-Up (mos) }\end{array}$ & Preop Sx & $\begin{array}{c}\text { Postop } \\
\text { Sx }\end{array}$ & $\begin{array}{c}\text { No. Preop } \\
\text { Meds }\end{array}$ & $\begin{array}{c}\text { No. Postop } \\
\text { Meds }\end{array}$ \\
\hline 1 & 2 & 15 & B & 15 & BP, RP, W & RP & 4 & 1 \\
2 & 3 & 10 & A & 10 & BP, RP & RP & 2 & 2 \\
3 & 3 & 11 & B & 11 & RP & none & 2 & 1 \\
4 & 3 & 15 & A & 15 & BP, RP & BP & 3 & 1 \\
5 & 3 & 10 & A & 10 & BP, RP, W & none & 2 & 2 \\
\hline
\end{tabular}

* $\mathrm{BP}=$ back pain; Meds = medications; $\mathrm{RP}=$ radicular pain; $\mathrm{Sx}=$ symptoms; $\mathrm{W}=$ subjective weakness. 


\section{Cortical bone trajectory screws for ASLD using spinal navigation}

receives royalties from Medtronic. Dr. Wesley Hsu receives research support from DePuy Synthes.

Author contributions to the study and manuscript preparation include the following. Conception and design: Rodriguez, $\mathrm{Hsu}$, Branch. Acquisition of data: Rodriguez, Liu, Somasundaram. Analysis and interpretation of data: Rodriguez, Neal, Hsu. Drafting the article: Rodriguez. Critically revising the article: all authors. Reviewed submitted version of manuscript: Neal, Liu, Somasundaram, Hsu, Branch. Approved the final version of the manuscript on behalf of all authors: Rodriguez. Administrative/technical/material support: Neal, Liu, Hsu, Branch. Study supervision: Rodriguez, Neal, Hsu, Branch.

\section{References}

1. Aiki H, Ohwada O, Kobayashi H, Hayakawa M, Kawaguchi S, Takebayashi T, et al: Adjacent segment stenosis after lumbar fusion requiring second operation. J Orthop Sci 10:490-495, 2005

2. Gillet P: The fate of the adjacent motion segments after lumbar fusion. J Spinal Disord Tech 16:338-345, 2003

3. Helgeson MD, Bevevino AJ, Hilibrand AS: Update on the evidence for adjacent segment degeneration and disease. Spine $\mathbf{J}$ 13:342-351, 2013

4. Kim CH, Chung CK, Park CS, Choi B, Hahn S, Kim MJ, et al: Reoperation rate after surgery for lumbar spinal stenosis without spondylolisthesis: a nationwide cohort study. Spine J 13:1230-1237, 2013

5. Lee CS, Hwang CJ, Lee SW, Ahn YJ, Kim YT, Lee DH, et al: Risk factors for adjacent segment disease after lumbar fusion. Eur Spine J 18:1637-1643, 2009

6. Lenke LG, Bridwell KH, Bullis D, Betz RR, Baldus C, Schoenecker PL: Results of in situ fusion for isthmic spondylolisthesis. J Spinal Disord 5:433-442, 1992

7. Levin DA, Hale JJ, Bendo JA: Adjacent segment degeneration following spinal fusion for degenerative disc disease. Bull NYU Hosp Jt Dis 65:29-36, 2007

8. Matsukawa K, Yato Y, Kato T, Imabayashi H, Asazuma T, Nemoto K: In vivo analysis of insertional torque during pedicle screwing using cortical bone trajectory technique. Spine (Phila Pa 1976) [epub ahead of print], 2013

9. Matsukawa K, Yato Y, Nemoto O, Imabayashi H, Asazuma $\mathrm{T}$, Nemoto K: Morphometric measurement of cortical bone trajectory for lumbar pedicle screw insertion using computed tomography. J Spinal Disord Tech 26:E248-E253, 2013

10. Mobbs RJ: The "medio-latero-superior trajectory technique": an alternative cortical trajectory for pedicle fixation. Orthop Surg 5:56-59, 2013

11. Mok JM, Cloyd JM, Bradford DS, Hu SS, Deviren V, Smith JA, et al: Reoperation after primary fusion for adult spinal deformity: rate, reason, and timing. Spine (Phila Pa 1976) 34:832-839, 2009

12. Moses ZB, Mayer RR, Strickland BA, Kretzer RM, Wolinsky JP, Gokaslan ZL, et al: Neuronavigation in minimally invasive spine surgery. Neurosurg Focus 35(2):E12, 2013

13. Okuda S, Iwasaki M, Miyauchi A, Aono H, Morita M, Yamamoto T: Risk factors for adjacent segment degeneration after PLIF. Spine (Phila Pa 1976) 29:1535-1540, 2004
14. Perez-Orribo L, Kalb S, Reyes PM, Chang SW, Crawford NR: Biomechanics of lumbar cortical screw-rod fixation versus pedicle screw-rod fixation with and without interbody support. Spine (Phila Pa 1976) 38:635-641, 2013

15. Radcliff KE, Kepler CK, Jakoi A, Sidhu GS, Rihn J, Vaccaro AR, et al: Adjacent segment disease in the lumbar spine following different treatment interventions. Spine J 13:13391349, 2013

16. Santoni BG, Hynes RA, McGilvray KC, Rodriguez-Canessa G, Lyons AS, Henson MAW, et al: Cortical bone trajectory for lumbar pedicle screws. Spine J 9:366-373, 2009

17. Sembrano JN, Santos ERG, Polly DW Jr: New generation intraoperative three-dimensional imaging $(\mathrm{O}$-arm) in 100 spine surgeries: does it change the surgical procedure? J Clin Neurosci [epub ahead of print], 2013

18. Shin MH, Hur JW, Ryu KS, Park CK: Prospective comparison study between the fluoroscopy guided and navigation coupled with $\mathrm{O}$-arm ${ }^{\odot}$ guided pedicle screw placement in the thoracic and lumbosacral spines. J Spinal Disord Tech [epub ahead of print], 2013

19. Spetzger U, Von Schilling A, Winkler G, Wahrburg J, König A: The past, present and future of minimally invasive spine surgery: a review and speculative outlook. Minim Invasive Ther Allied Technol 22:227-241, 2013

20. Tabaraee E, Gibson AG, Karahalios DG, Potts EA, Mobasser JP, Burch S: Intraoperative cone beam-computed tomography with navigation (O-ARM) versus conventional fluoroscopy (C-ARM): a cadaveric study comparing accuracy, efficiency, and safety for spinal instrumentation. Spine (Phila Pa 1976) 38:1953-1958, 2013

21. Ueno M, Imura T, Inoue G, Takaso M: Posterior corrective fusion using a double-trajectory technique (cortical bone trajectory combined with traditional trajectory) for degenerative lumbar scoliosis with osteoporosis. Technical note. J Neurosurg Spine 19:600-607, 2013

22. Van de Kelft E, Costa F, Van der Planken D, Schils F: A prospective multicenter registry on the accuracy of pedicle screw placement in the thoracic, lumbar, and sacral levels with the use of the O-arm imaging system and StealthStation Navigation. Spine (Phila Pa 1976) 37:E1580-E1587, 2012

23. Wang J, Zhou Y, Zhang ZF, Li CQ, Zheng WJ, Liu J: Comparison of one-level minimally invasive and open transforaminal lumbar interbody fusion in degenerative and isthmic spondylolisthesis grades 1 and 2. Eur Spine J 19:1780-1784, 2010

24. Xia XP, Chen HL, Cheng HB: Prevalence of adjacent segment degeneration after spine surgery: a systematic review and meta-analysis. Spine (Phila Pa 1976) 38:597-608, 2013

Manuscript submitted November 15, 2013.

Accepted January 10, 2014.

Please include this information when citing this paper: DOI: 10.3171/2014.1.FOCUS13521.

Address correspondence to: Analiz Rodriguez, M.D., Ph.D., Wake Forest University School of Medicine, Medical Center Blvd., Winston-Salem, NC 27157. email: arodrigu@ wakehealth.edu. 